\title{
Linear parks understood as vertebration instruments of the city
}

\section{Ignacio Bosch Reig, Luis Bosch Roig, Valeria Marcenac, Nuria Salvador Luján}

Instituto Universitario de Restauración del Patrimonio. Universitat Politècnica de Valencia. Valencia, Spain

E-mail: ibosch@pra.upv.es; luibosro@pra.upv.es; marceval@pra.upv.es; nusalluj@pra.upv.es

\begin{abstract}
This research raises as thesis the idea that Linear Park is an urban instrument capable of vertebrate the city and, consequently, of regenerate it. To this end, ten parks strategically located in big cities such as Rio de Janeiro, London, Paris, Madrid, Barcelona, or in medium or small cities such as Valencia, Castellón or Figueres, have been analyzed. Of this analysis we have deduced some characteristics that are considered key in the linear and transversal vertebration of the city, such as: green axis-corridor approach; sequence of events with integration of public buildings; continuity derived from the union of different areas; promotion of active leisure activities, individual or collective: sports, cultural, ..., capability of relation and regeneration of ecosystems: forest, meadow, orchard, nurseries, water, city, ...; capability to restore environment, with reduction in $\mathrm{CO} 2$, in noise pollution, ...; establish relations between the city and the territory with definition of natural parks; contribute to prevent thermal inversion in the city; establish a beginning and an end as recognizable elements in city; confrontation of opposites: static or dynamic; soft (green) or hard (pavement); unitary or fragmentary, cartesian or organic, ... The parks thus understood can be organized in diverse typologies, such us: classic order; in net; upholstery-continuous map; linear order with grooves, tapes or bands; landscaper and naturalist; ... The work delves into these themes by recognizing tools of interest such as: harmonic relationship; human scale; non-guided tours; sensory experimentation: spaces, sights, aromas, sounds, colorful, ...; unexpected and random; pragmatic and passionate; order within disorder; activation of spaces without hierarchies or apriorisms; flee from monotony; evocations; ...
\end{abstract}

Keywords: Linear park, green corridor, city vertebrator, urban regeneration, sensorial experimentation, harmonious relationship.

\section{Introduction: to recover the scale of the city}

The thesis proposed by this text is that linear parks within cities can be a highly effective instrument for integral, sustainable and participatory urban development, capable of transforming the city and consequently regenerating it.

In order to study the keys for linear parks, it is convenient, as always, to go back to the origin and to recognize in history how they have arisen and how they have evolved from what can be described as elemental linear park, to the current parks of Great complexity.

First actions: row plantings on roads and roads outside the walls

In 1552, Henry II King of France ordered "all lords, the justices, and all the rulers and inhabitants of cities, towns and parishes, to 
plant and planting along roads and as good public roads and A large number of the socalled elm trees that over time our kingdom has been sufficiently populated "

Nearly two centuries later, in 1825 , the Ponts et Chaussées service systematically planted tree lineages on the roads for its own exploitation, with a triple purpose: to mitigate the lack of wood after medieval deforestation, to beautify the roads, and to affirm the State power.

Recommendations are made for the said plantation, depending on the width of the road and the perception to be obtained, defining variable distances between the trees (4 to $20 \mathrm{~m}$ ), and between these and the road itself (2.5 to $6 \mathrm{~m})$.

With this and according to the type of tree to be planted, of vertical growth like the elm trees or horizontal with wide glass like the bananas, it was possible to define diverse landscape perceptions like for example: row of trees very dense perceived like a directional green line, that acted Of reference from the great distance, and as a shadow for the traveler, from the short distance; Or the channeling of the road with double row of trees, with a sequential arrangement perceived as a protection for the traveler.

This second form of double-row plantation is the one that masterfully used André Le Notre, in the seventeenth century, in the definition of the Allées (tree-lined walks) of Versailles and many other French-style gardens. Le Notre, uses the Allée, not only as a walk that picks you up, protects you and takes you forward, but also and above all as a directional mechanism that remarks the perspective towards a great stage finale, such as the Palace of Versailles , Or as an instrument to establish certain optical illusions, supported by the play of light and shadow, transparencies, sound of water, chromatic changes, ...

One of the most important contributions

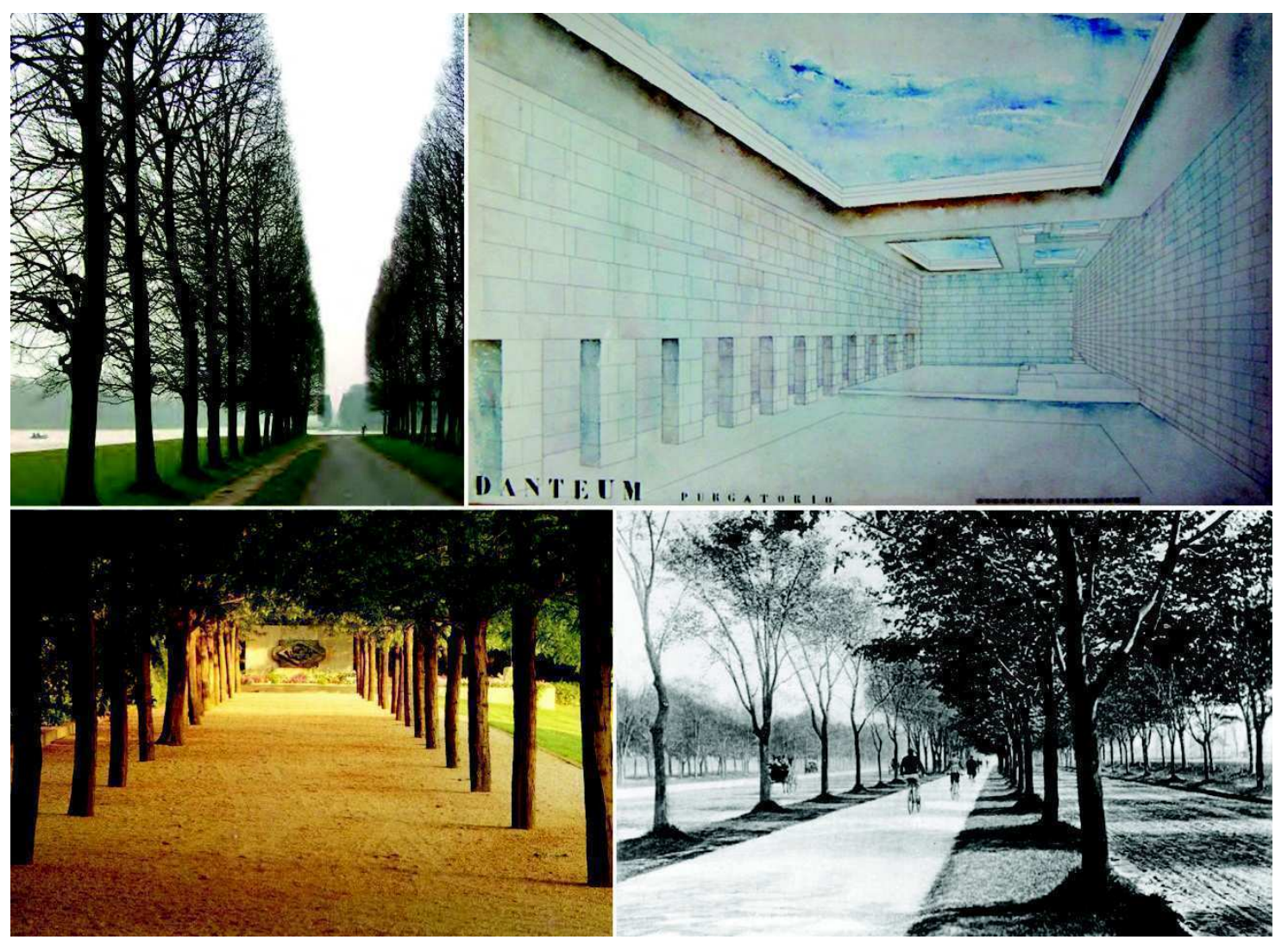

Figure 1.

Allée du Canal. Versalles. Andre Le Notre, s. XVII; Salt Danteum Purgatory, Giuseppe Terragni, 1938; Allée of Chestnut Miler Hause Garden, Dan Killey, 1953-1957; Ocean Parkway, Brooklyn, Frederick Law Olmsted, 1860-1880 
of Le Notre in Versailles is the different configuration of the architectural space through the arrangement of the trees, obtaining not only a directional space, but also that it becomes a large window towards the celestial vault, able to frame A fraction of it, attracting it to the observer, who became the ceiling of space, as centuries later Giuseppe Terragni recreated in the room of the purgatory of the Danteum, projected in 1938. (F01)

In the same way, Le Notre, is able to define the closed vertical space, by having double rows of bananas in the Allée Real, which grows even above $40 \mathrm{~m}$ in height, their cups come together, establishing a space where the component Vertical, that which Christian Norberg-Schulz defined as the sacred tension of architecture.

This approach to the definition of architectural space through the use of tree plantations is a theme that has remained in time in a way that modernity has assumed as its own. A good example of this is the Miller Hause Chestnut Allée, made between 1953 and 1957 by Dan Kiley, in perfect harmony with the traces of the house designed by Eero Saarinen and Kevin Roche, forming a beautiful garden, where the formal essentialization of the Zero ground plane, in earth or green tones, acts as support for the rational sequence of the double row of chestnut trees, whose trunks arise from the ground with perfect circular section, we are shown as a classic double colonnade, where the entablature, Covered are replaced by the tree tops that join us in an architectural space full of nuances and suggestions. (F02)

In Europe, this system of plantation of trees in the territory creating Allées, approach the walled cities establishing external perimetral walks, so that at the end of the XVIII with the demolition of the walls, they become part of the structuring of the city, Becoming what we know as boulevard.

In the United States, this process of introduction into the city of the incipient linear park, is produced in the nineteenth, through the great landscape architect Frederick Law Olmsted, who in addition to designing many of the present great parks of American cities, such as Central Park New York, developed a system of tree plantation, similar to the Allée, called
Parkways or avenues. The great difference and contribution of Olmsted is to understand this issue as a system of urban planning, so that the growth of the American city, an extensive city of low density, occurs from that moment with a repetitive sequence in parallel, zone Of houses giving a green corridor with four or six rows of trees (parkways), establishing the transverse relationship, in addition to the directional. (F03)

One theme that appears systematically in these examples, both European and American, is the sought unity of formal criterion in the definition of the walk, so that chosen the type of tree, this is repeated throughout the entire route of the Allée, the Boulevard or parkway.

However, at the beginning of the XVIII century, in Valencia (Spain), the plantation of the Alameda Allée is produced, whose distinctive feature is the diversity of the woodland that forms it, introducing tropical species, which give it a marked pluralistic, very close to the eclecticism that will prevail a century later.

\section{Contribution: enjoy sensory - experimentation}

In any case, these tree plantations in row, whether in the territory or structuring the city, when they travel, introduce us to a first sensorial enjoyment, where the slight or accelerated movement of the leaves produced by the roar of the wind, next to the Effects of transparency and reflections of light and shadow, establish an atmosphere of multiple sensations.

At present, and for some decades, one of the key issues in the design of linear parks, is precisely the search for the user, sensory experimentation, so that the choice of materials (pavements, street furniture, Illumination, ...) of plant species, and their relative disposition, are posed so as to activate the five senses of the observer, inciting him to contemplate, to caress, to smell, to hear, to perceive, to feel.

For this, it is essential to know the plant species well, its evolution along the four seasons, type, color, size, shape of flowering, .... seeking learning through the senses, through the diversity of textures, Flavors, 


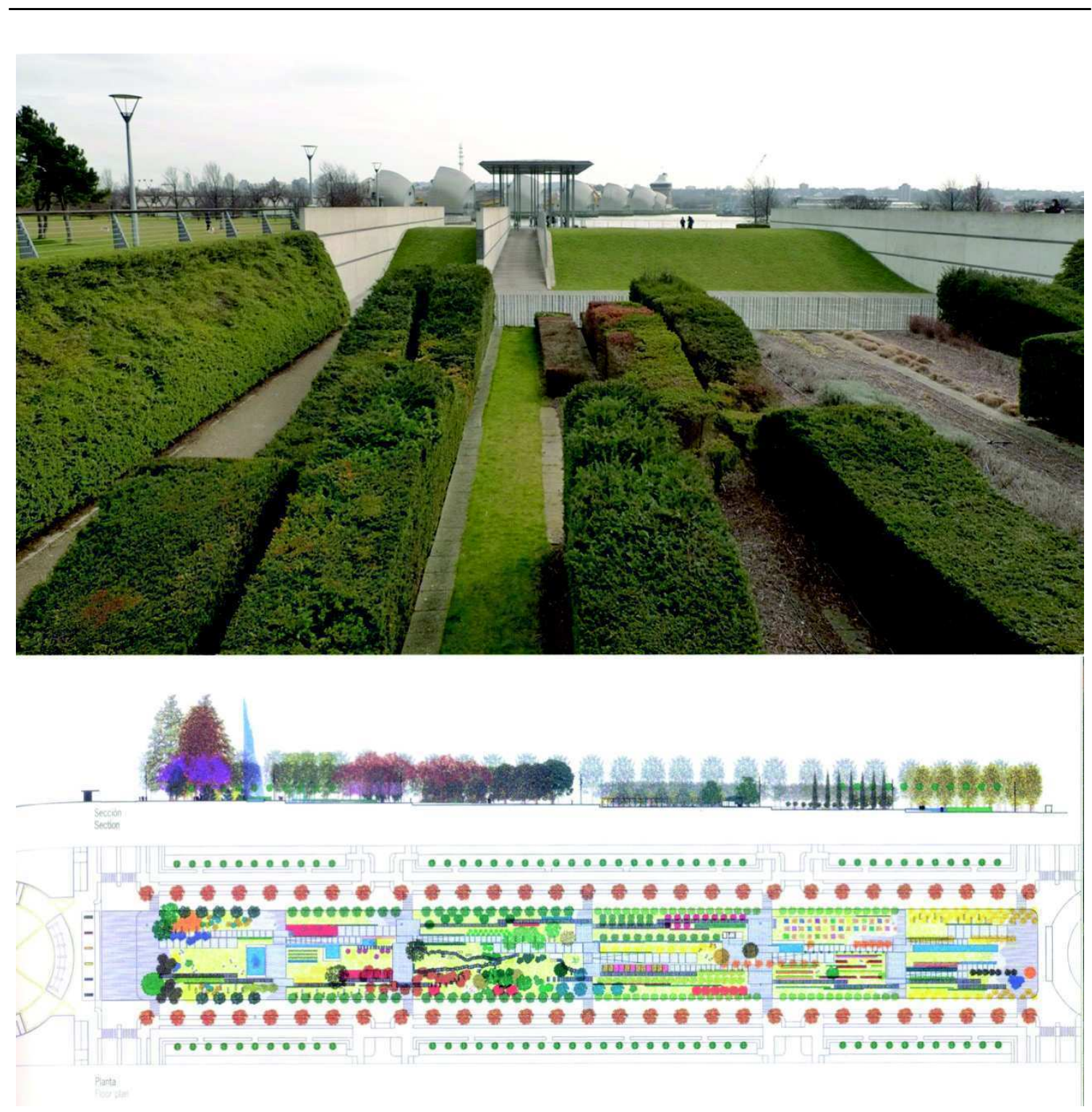

Figure 2.

Thames Barrier Park in London. Group Signes, 2000; Campus Riu Sec. University Jaume I. Castellón (Spain). M. Del Rey, I. Madro, A. Gallud, Mª T. Santamarina. 2004

aromas, sound elements, colorful, shapes, sizes, blooms, ...

Many are the examples that base their design on the long-awaited sensory experimentation, but it may be useful here to highlight two of them. The first is the performance of the Signes Group at the Thames Barrier Park in London, where, from the concept of the park within the park, they establish a diagonal green pier, like a vegetable river, organized on the basis of parallel bands, Which arise from the earth as linear wave-waves of different heights, imparting a strong dynamism, introduces us to sensory enjoyment through the sequence of aromatic plants such as rosemary, thyme, lavender, basil, sage, herbal, etc. The sensory experience occurs from the apparent formal, vegetal and chromatic unity, which can scratch monotony for the observer.

The second example, "the Riu Sec Campus of the Jaume I University of Castellón (Spain), designed by the architects Miguel del Rey, Iñigo Magro, Antonio Gallud and María Teresa Santamarina, bases its design on the diversity of the performance, variety of Species, shapes, colors, aromas, images, sizes, blooms, .... If in the above example sight and smell were the two key senses in experimentation, in Riu Sec, it is the combination of the five senses, which gives strength and quality to the whole. (F04) 


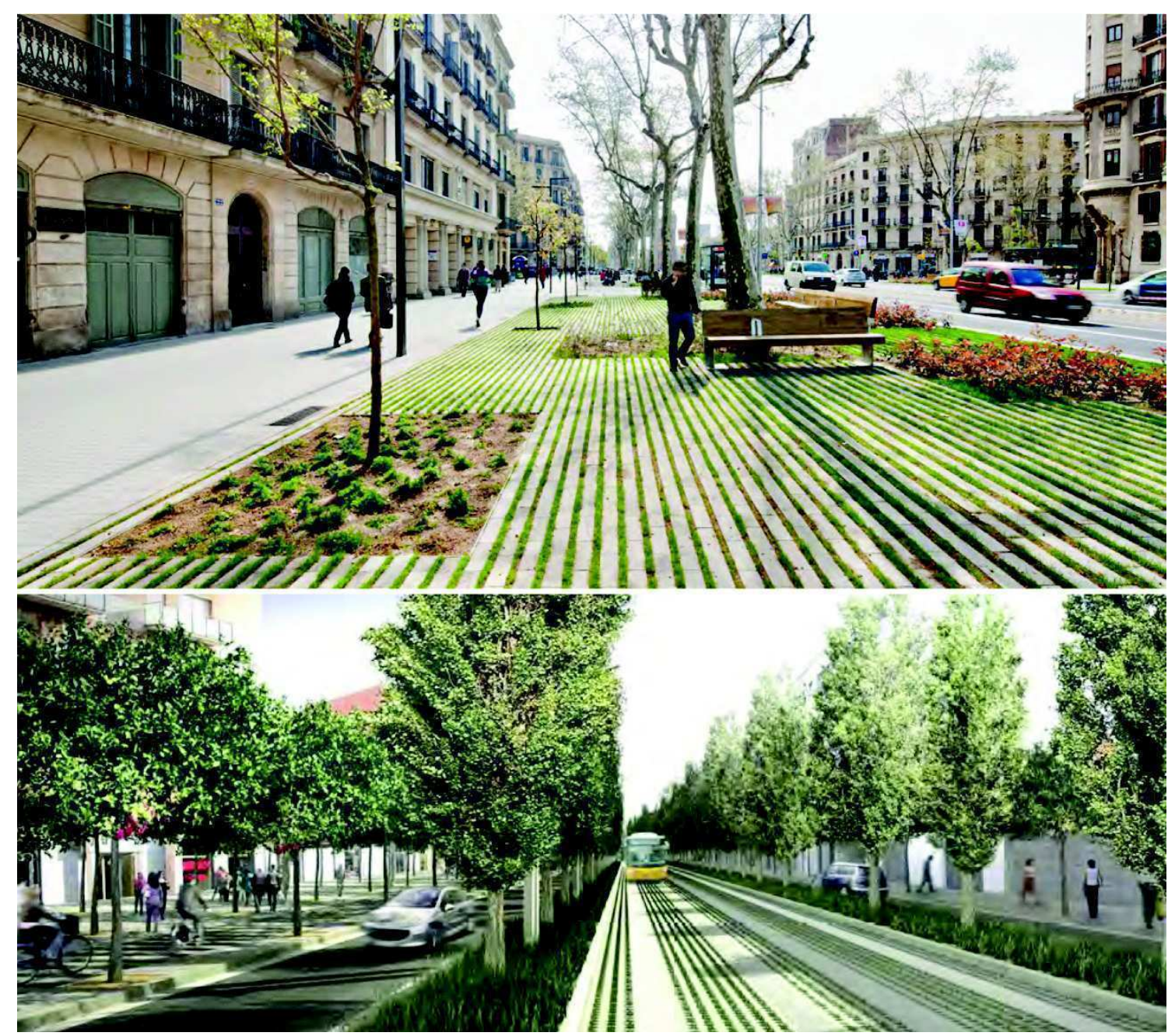

Figure 3.

Passeig de Sant Joan de Barcelona. Lola Domenech 2010 and 2011;

Bus lane Cornella Castelldefels, Bajo Llobregat, Barcelona. Batle and Roig, 2008.

\section{Contribution: natural-artificial integration}

One of the most difficult issues to achieve in translating the concept of linear park into the city, through any of the aforementioned figures, such as boulevards, is precisely that necessary relationship between its natural-vegetable origin and the artifice of The construction of urban space.

Some example will help us understand if this integration is possible. We refer to the performance of Lola Domenech in Passeig de Sant Joan in Barcelona, conducted between 2010 and 2011, in which it achieves the sought-after nature-artifact fusion, defining a single horizontal plane in which in a simple and clean, interlock The vegetation, the trees and trees, the pavement, the flower beds, the urban furniture, .... Establishing an exquisite harmonic discourse.

In this direction, the group of architects Batle and Roig, in 2008, in the design of the bus lane from Castelldefels to Cornellá, of the Bajo Llobregat of Barcelona, take a further step in this desired direction, and they intend to achieve a total integration between the Stay, the walk, the public transport, the bike path, ....

Defining it as a real green corridor. (F05)

\section{Contribution: new city vision from above}

If we have been talking about "elementary linear parks" so far, we can refer here to "complex linear parks", starting with the High Line of New York (2004 competition 


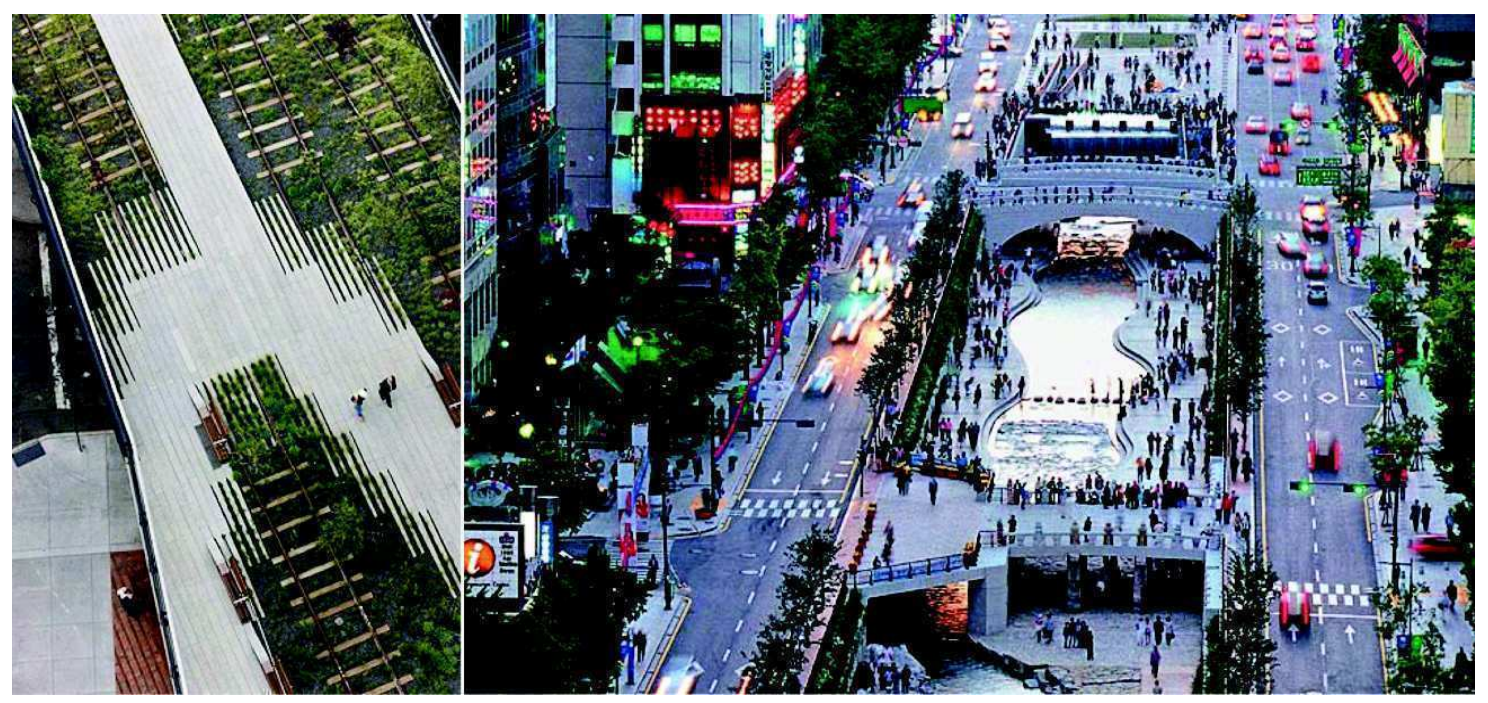

Figure 4.

High Line, New York. James Corner Field Operations, 2004-2015; Cheong Gye Cheon F07- Arroyo. Kee Yeon Hwang, 2003 and 2005.

and Execution from 2010 to 2015), which has marked a new way of designing a linear park, in which concepts such as recycling, or natural spontaneity, arise from the very bowels of it. (F06)

The idea of the High Line arises when it loses its use a railway infrastructure that from 1930 to 1980 , supplied raw materials, besides milk, meat, ... to certain factories located in a route of $2,33 \mathrm{Km}$, to $9 \mathrm{~m}$ of height on the map of the city.

This idea is not the first time that it arises, since in 1988-93 the landscaper Jacque Vergely and the architect Philippe Mathieux realized it in the Coulée verte René-Dumont of Paris (le Promenade Plantèe), reusing an abandoned railway line Since 1980, so that the first stretch from the Opera de la Bastide to the garden of Reuilly, the linear walk is located above the viaduct of Arts, $10 \mathrm{~m}$ above the level of the city. However, the difference lies mainly in the concept of the design, since the Paris is based on a classic approach to the garden, far from the contributions of the High Line.

This, based on the concept of recycling, which tries to print a new cycle of life to the preexisting that has lost its validity, proposing the reconversion of an urban vital industrial infrastructure, in a post-industrial tool of leisure, life and increase. And this is intended to be achieved by making spontaneous growth of nature in abandoned land, so-called "weeds", take quality charter, and emerge as a new and simple way of using the natural. This way of acting, produces a change in the hitherto rules of the man-nature relationship, which makes it more suggestive and unpredictable.

It is considered as the opportunity to have and participate in a new, changing experience, linked to the discovery of the city itself from a different view, or the observation of a spontaneous, diverse, and continuously changing nature. The High Line, is not a finished and closed work, is the opposite, a work in process, open to new incursions. It is therefore flexible and offers a great capacity to respond to the changing needs and opportunities and desires of society.

Its route, west of Manhattan, from Ganservoort Street to 34th Street between Avenues 10 and 11, has a clear tourist attraction, since from there you can see the Statue of Liberty, the Empire State Bulding, the Hudson River And the financial district. It has 10 access points, so some are produced ascending through the center of the Line, to get the visitor to enter the park from the inside, impregnating with its attractive attractions.

A green axis is designed, where wooden paths, rest areas, eating places, cultural spaces for temporary shows, exhibition and small shops arise. The work is based on recreating the old links and rail lines, with large flower gardens and small more pauses. 
Materiality is established as one of the key themes in the definition of an "almost natural" green axis, where the usual artificiality of the urban space is brought back to a spontaneity in which the instruments of design tend to go unnoticed. In this way the lighting is done with leds arranged in the ground plane, under the furniture, in a sequential way illuminating the paths. The pavements are prefabricated concrete, with a friendly finish in Ipe wood, recycling the original metal structure, such as railroad tracks, Art Déco railings of the original stairs, .... The vegetation is diverse in its shape, image, colorful, textures, ... grass, shrubs, bulbs, evergreens, tropical plants, .... Here too the observer is introduced into sensory enjoyment.

\section{Contribution: linear and transversal vertebration of the city}

If the case of the High Line commented on the recycling of an outdated infrastructure turning it into an autonomous pedestrian walkway as a green corridor, producing a linear structure of the city, the typology of linear park that is discussed in this section, raises as contribution The double structure of the city: linear and transverse, sewing neighborhoods-areas that were previously clearly separated by a natural barrier such as a river, or artificial as a traffic infrastructure of heavy traffic.

The purpose of vertebration is established from the idea of continuity obtained from the union of diverse areas, giving rise to a sequence of events, sometimes unforeseen that arise spontaneously, and others clearly announced, through the integration of equipment.

This type of linear parks seek in their design to accommodate multiple active leisure activities, both individual (cycling, running, walking, doing gymnastics, ...), as a collective (sports, racing, games, ...) and family as It is the leisure, the walk, the games of children, ...

An interesting case in this direction is the work done by the team of urban planner Kee Yeon Hwang between 2003 and 2005 in the recovery of the historic Cheong Gye Cheon stream that runs from west to east in the center of Seoul, eliminating the highway built in 1968
On it, turning it into a linear river park as an attractive place, for the use and enjoyment of the citizen, in which the "soft" areas with vegetation accompany the water course, and the "hard" zones where there is a Integration between the pavement, the stands and the water sheet, which thanks to mechanisms such as water, is achieved that is at rest, which allows their use by people. (F07)

The sought and well achieved transverse vertebration of the city, in this case is established through several mechanisms: the continuity of the cross streets through 22 bridges; The cross-sectional design of the park in a friendly manner, where tree-lined sidewalks, vehicle lanes, park-river and pedestrians are easily related; The connection between the level of the city and that of the park, in most crossconnections; And finally the direct connection of certain equipment located in the margins.

This action has become a real operation of urban renewal, in which, in addition to achieving the city's structure, new objectives of sustainability and ecology have been covered, substantially improving air quality (by eliminating pollution from the previous motorway ), Reducing the "heat island" effect with a temperature drop of $3.5^{\circ}$ in relation to neighboring neighborhoods, and creating a new natural habitat where many plant and aquatic species have found the right ecosystem for their existence, becoming In the lungs of the city.

Thus, with an intense citizen participation, the Cheong Gye Cheon recovery has meant much more than removing an obsolete infrastructure, or the nostalgic recovery of a forgotten river. In fact it has become a generator of new activities, new ways of living, new relationships, resulting in a radical change in downtown Seoul, enhancing civic life, which had almost disappeared.

\section{Contribution: recovery of history}

This type of operations of linear and transverse vertebration of the city, is a recurrent theme, that already was put into practice in the city of Valencia (Spain), back in the seventies, when recovering as a public park, the old River 

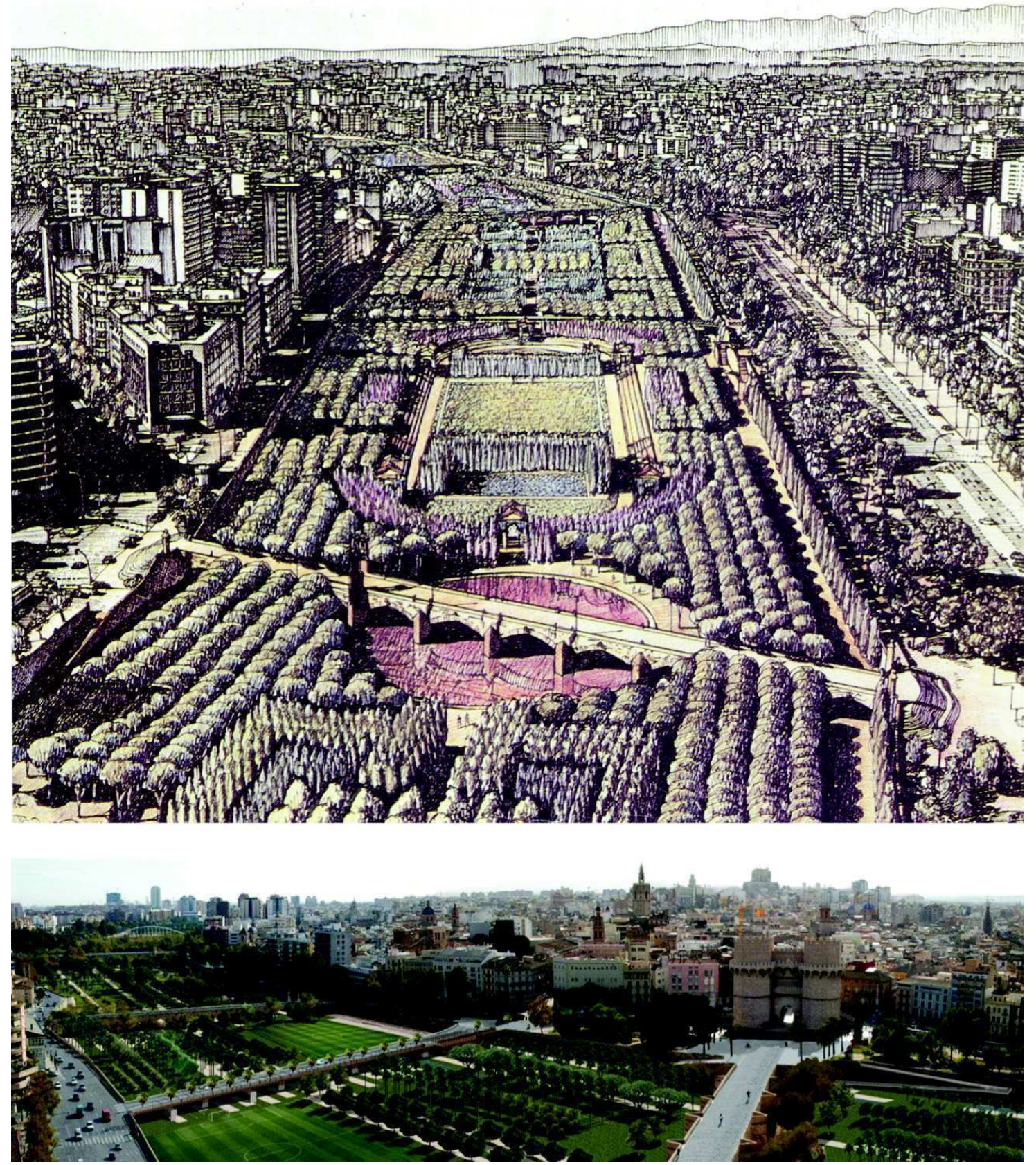

Figure 5.

Parque del Turia, Valencia (Spain). Ricardo Bofill, 1975; Restoration bridges Trinidad and Serranos Parque del Turia, Ignacio Bosch, 2005.

Turia, whose use as a river had ceased to exist since 1968 with the construction between 1961 and 1968 of a new and peripheral channel that solved a continued danger of floods suffered by the city ( 89 between 1300 and 2000), especially the devastating 1957.

The initial approach of the new Turia linear park, based on the Ricardo Bofill project of 1975, proposes to obtain the concept of unity through the tree mass that acts in full, over which, through systematic subtraction operations, Empty as elementary spaces, which are organized geometrically in a classical order, establish a harmonious relationship between them, in which different events take place, with sports, leisure, recreation, cultural activities ....

This sequence of activity spaces, located in the center of the tree mass, is defined by simple 


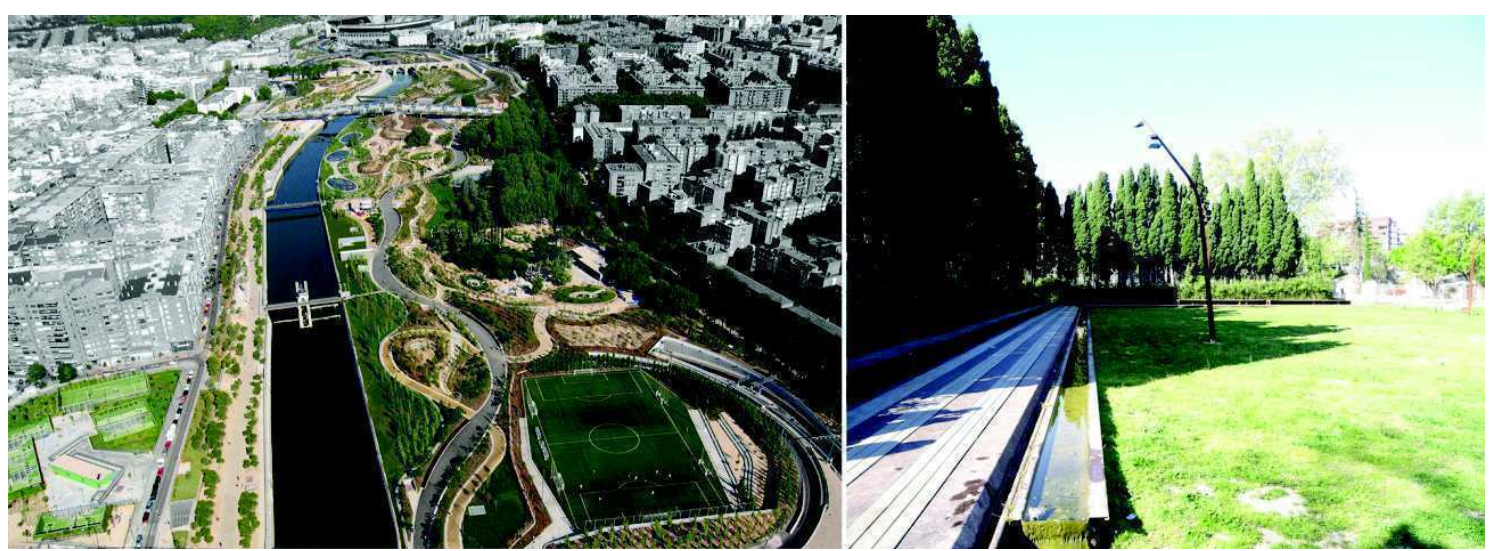

Figure 6.

Parque Manzanares, Madrid (Spain). Burgos and Garrido; Porras and Caste; Rubio and A. Hall; and West 8; Water Park, Figueres, Girona (Spain). Michèle Orliac and Miguel Batlle.

and direct geometries such as the circle, the square or the rectangle, which are perimetrally supported by individual linear paths for pedestrians and cyclists. In them, the water at rest as a reflective sheet, or in continuous movement, introduce us again into the sensory enjoyment, perceiving an endless number of variations of light, shadow, reflections and sounds.

The river Turia, having no water for most of the year, was historically used as a place of recreation, where cattle fairs were set up, public laundry, .... So that several of the stony bridges of the XV and XVI centuries, had stairs or ramps of descent of carriages for their connection with the level of the city. Or spaces of wardens, on the Tajamares, that acted of viewpoints and zones of rest. All these elements were partially dismantled in 1810 , with the war of the independence, in an attempt to prevent the taking of the city by the French.

With the restoration project of the historical bridges of Trinidad and Serranos, carried out in 2005 by the team of the Universidad Politécnica de Valencia, led by the architect I. Bosch, one of the key themes of the linear park Of the Turia, which has been precisely the recovery of both the public uses that historically developed in it and the urban elements that had disappeared at the beginning of the nineteenth, so that both the bridge of the Trinity and Serranos, Stairs and descents have been recovered at the level of the river bed, as well as the stewardesses from which a calm view of the landscape of the city is allowed. (F08)

In this way, the Linear Park of Turia, which crosses the center of the city of Valencia over $17 \mathrm{~km}$, has become the green lung of the city, and at the same time the mechanism of transverse vertebration, establishing important connections Cultural center between the West, the historical center, with its monuments, palaces and museums such as the IVAM, and the East area, where is located the museum of St. Pio V, Palau de la Música, Gardens of Nurseries, ....

\section{Contribution: regeneration of ecosystems - sustainability}

But it has been in the last two decades, when we have become aware of the need to propose a sustainable design, which allows the regeneration of ecosystems, from a naturalisticlandscape concept of the linear park.

And this approach has been developed from large operations with a high economic cost but at the same time with results of great benefit to society, or through operations of small investment but of great interest for their conceptual relationship with the natural space.

Among the first is Operation Madrid Rio, with the Manzanares Park, the result of a competition won by the team formed by the architects: Burgos and Garrido; Porras and $\mathrm{La}$ Casta; Rubio and A. Sala; And West 8. (F09)

The new line park of the Manzanares 
emerged as a result of the burial of the motorway that bordered the river bank, had become an impassable barrier, which had segregated the neighborhoods of southern Madrid, disconnecting them from citizen life.

The operation goes beyond the scope of the city, establishing a $60 \mathrm{~km}$ route, which begins in the town of Manzanares del Real, and passing through Madrid, ends in the city of Aranjuez, regenerating the ecosystems of the territory through which it moves The river Manzanares.

In the interior of the city of Madrid, and crossing from north to south, the River Manzanares has become a large linear park, partly fluvial, made based on sustainability criteria such as: universal accessibility with slopes of 4 to $6 \%$; The reuse of land coming from the excavation to bury the highway, which in turn assumed the reduction of $35,000 \mathrm{Tn}$ of $\mathrm{CO} 2$ from the air pollution, as well as the elimination of noise pollution.

With the planting of 34,000 trees, the park has an important vegetable quality, which is organized by looking for unity within diversity, so that the linear pine walk that is arranged throughout the park, is combined with masses Trees of different species but homogeneous in themselves.

The elimination of the road barrier and its replacement by the park has meant the connection and transverse structure of the city, linking the south with the central zone, and producing an intense urban regeneration based on the concept of landscape-city integration.

In the park again appears the sequence of diverse events, with integration of equipment, services, sports activities, peripheral urban parks, .... But also the quality of the indetermination that allows to realize new experiences not programmed, ...

\section{Contribution: city-territory relationship. natural park}

Among the activities that achieve a sustainable naturist-landscape design, with a very limited investment, we should highlight the Parque de las Aguas, made by landscape architects Michèle Orliac and Miguel Batlle, in Figueres, Girona (Spain)
The park is configured from the recovery of the natural territory, with minimal intervention, reusing the existing elements such as the pool, using a single artificial material, such as sheet metal, which serves equally to contain the land, to become Water channel, to define the pathwalk, the bank run, ....

This type of actions can recover a natural territory, reconvert it into an urban park, integrating nature with the artifice, showing a high capacity for regeneration of the ecosystems: forest, meadow, orchard, nurseries, water, city, ..., Environment, with $\mathrm{CO} 2$ reduction, noise pollution, ...

\section{Conclusion}

Undoubtedly the urban linear park as well as being a driving force for the regeneration of the city, with a green corridor-axis approach, which is configured based on the sequence of events with integration of facilities, which promote individual active leisure activities, familiar, collective, sports, cultural,..., producing its directional and transversal vertebra, has evolved towards sustainable design, whose most relevant characteristics can be summarized in the following:

-ECOL support system or logical or $n$ $r$ egeneraci of natural spaces, such as the restoration of wetlands, native plants, forests, grasslands, Orchard, nurseries, $\ldots$ of the landscape of the place.

-Use of natural landscape elements rooted in the area, as flowing water, water lilies, ....

-Recycling of materials and structures, with realization of new bioclimatic energy efficient architecture.

-Efficient stormwater mamagement, with efficient illumination.

-Universal accessibility.

-And as always, a good design is based on the tools of architecture as the binomial lightshadow, the control of scale, the confrontation of opposites: static or dynamic; Soft (green) or hard (pavement); Unitary or fragmentary, Cartesian or organic, .....

This allows to recognize positive results for the city and the citizen, as they are:

-The restoration of wetlands, orchards, 
grasslands, and forests undoubtedly drastically improves the quality of air, water and biodiversity

-In the parks of sustainable design, the fauna and flora regenerate, there is fishing, the birds nest, ....

-The ecological system is reinforced with this type of actions that produce the recovery of the native ecosystems.

-The collection and efficient management of rainwater reduces the demand for drinking water by an important percentage.

- There is a strong decrease in $\mathrm{CO} 2$ from environmental pollution, as well as a reduction of noise pollution, so that the arboreal mass of the park acts as an absorbent mattress, and helps to avoid thermal inversion in the city

-It establishes new and intense relations between the city and the territory with definition of natural areas.

In short, an ecological linear park obtained through a sustainable design, becomes the lung of the city and acts as its symbol of vitality.

\section{References}

AAVV, "Jardin del Turia", "Valencia Architecture Guide" CTAV 2007

Besomi, Andrés, "Project Madrid-R í o / Burgos \& Garrido, Porras La Casta, Rubio A. Hall, West 8". Platform Architecture, 2011

Blasco, José A ., " (renewal or urban $\mathrm{n}$ from the Cheong Gye Cheon in downtown ) ". Urban Networks, 2015

Bosch, Ignacio. “ Interventi sui Ponti storici Trinidad and Serranos Valencia Work on The Historic Trinidad and Serranos bridges in Valencia “. Disegnare, Idee immagini . $\mathrm{N}^{\circ} 42,2011$.

Bosch, Ignacio. "The ruin as added value in equity. The non finite". Magazine: Engineers í ay Territory, 2011.

Bosch, L1.; Herr to ez, J .; Denia, J .; Navarro, $\mathrm{P}$; Bosch, I. " Structural reinforcement of a historic bridge to Ensure stability by laser - guided drilling ." Journal of Cultural Heritage . 1, pp. 1 - 9. 2012.

García, Laura. "The gardener of the Sun King: The gardens of André le Nôtre in the France of Louis XIV.“. History 16 n u m. 293: 2000.
Geiger, D. " High Line ' s high returns ". Crain 's New York. 2014

Terragni, G.. “ Relazione sul Danteum “. Draft memory. 1938.

Javier And to var, "Landscape and Architecture: remodeling or $\mathrm{n}$ the Paseo de St. Joan, a new urban green corridor by Lola Domènech . Platform Architecture, 2014

Norberg-Schulz, Chr. : Western architecture . Barcelona, Ed. GG, 2001 (1979)

Robert Twombly, ed. (2010): "Frederick Law Olmsted : essential texts", WW Norton \& Company, New York

Stephens, S. "Miller House and Garden". Architectural Record. Retrieved 5 May 2011.

TC 91- Batlle i Roig Arquitectes. Architecture 1996-2009. Valencia 2009 